\title{
Algorithm of conversion of meteorological model parameters
}

\author{
David Šaur, ${ }^{1, *}$ and Juan Carlos Beltrán-Prieto, ${ }^{2, *}$ \\ ${ }^{1}$ Tomas Bata University in Zlin, Faculty of Applied Informatics, Nad Stráněmi 4511, Zlin, Czech Republic \\ ${ }^{2}$ Tomas Bata University in Zlin, Faculty of Applied Informatics, Nad Stráněmi 4511, Zlin, Czech Republic
}

\begin{abstract}
This article is focused on the forecasting severe storms with the Algorithm of Storm Prediction as a new forecasting tool for the prediction of the convective precipitation, severe storm phenomena and the risk of flash floods. The first chapter contains information about two applications on which basis are computed forecast ouptuts of this algorithm. Further, this chapter is also objected on more detailed descripition of the second application known as the Algorithm of conversion of meteorological model parameters . Predictive outputs generated by this algorithm are verified on 63 storm events, which is occurred in the territory of the Zlín Region in 2015-2017. The results chapter solves the comparison of the success rate of the manually and computed-processed outputs calculated in the Algorithm of Storm Prediction. Primarily, these outputs will be used for increasing efectivity of preventive measures against flash floods not only by the Fire Rescue Service, but also by flood authorities and crisis management bodies.
\end{abstract}

\section{Introduction}

Forecasting of severe convective storms and its impacts as torrential rainfall, hailstorm, strong wind gusts and tornadoes is one of the most difficult predictive activities of all meteorological services and research centres. Main problems consist in the prediction of the dynamic-development severe convective storms, which can occur on the greatly small territory with few square kilometres after meso-synoptic convective storms (MCS) of the area several tens to hundreds square kilom etres [1], [2], [3], [12], [19]. Whereby, the forecast of local occurrence of severe convective storms is more complicated due to an insufficient amount of data from the ground and aerological stations.

Forecasting of severe convective storm has been investigated and implemented in the numerical weather prediction models (NWP models), nowcasting systems and expert meteorological systems. All these systems have serious restrictions in the forecasting of convective precipitation and other severe storm phenomena. And for the reason these systems are very difficult to use for the compilation of the accurate predictions of precipitation with sufficient length of forecast.

Nowcasting systems operate with products of radar measurement for purpose the calculation of the expected trajectory and precipitation occurrence through the selected extrapolation methods. Disadvantages of these systems consist in the principle of the radar measurement, which cannot predict especially local rainfall due to its intensively and dynamic-development in a short time. Simultaneously, nowcasting systems provide forecast information for a very short time, approximately 60 minutes which is for purpose of crisis management in terms of the deployment rescue forces completely inadequate [4], [5], [6].

NWP models can more accurate predict convection precipitation assuming use non-hydrostatic core model intended for modelling atmospheric convection. On the other hand, non-hydrostatic core models are experimentally used for orientation and complementary forecast; however, these models have been very little applied in the predictive practise. Meteorological institutions work more often with hydrostatic models supplemented by the parameterization of convection, which allow to predict weaker convection or severe convective storms (MCS) influencing the large territories [7], [8], [9]. The prediction of local and intense convective precipitation usually reaches a large number of errors and inaccuracies. Therefore, these predictive tools are combined with Flash Flood Guidance systems that work with other parameters such as soil saturation in the FFG-CZ project [12]. These systems provide more comprehensive predictions about the flash flood risk than NWP models and nowcasting systems [10], [11], [12].

The shortcomings and technical limitations of these systems rapidly reduce the success rate of predictions of convective precipitation and severe storm phenomena. Based on these limitations, the Algorithm of Storm Prediction has been developed as an analyticalevaluation application to refine predictions of convective rainfall and severe storm phenomena for smaller territorial units than regions with sufficient predictive length of forecasts to 24 hours [3]. This paper is focused on the description of two main applications, of which the

* Corresponding author: $\underline{\text { saur@utb.cz }}$ 
Algorithm of conversion of meteorological model parameters is analyzed in more detail and verified on 63 situations for the years 2015 to 2017 for the territory of the Zlín Region.

\section{Methods}

Forecasting of severe convective storms, whose impacts as torrential rainfall, hailstorms, strong wind gusts and tornadoes may cause flash floods, has been solved by the Algorithm of Storm Prediction with these algorithms:

1. Algorithm of transformation of output meteorological parameters.

2. Algorithm of conversion of meteorological model parameters [13].

Algorithm of Storm Prediction is consisted of these algorithms implemented to two desktop applications. This algorithm provides prediction information about Probability of convective precipitation occurrence include its Storm intensity, Risks of severe storm phenomena and flash floods. Forecast length is 3-24 hours and prediction territories are 206 municipalities with extended powers of the Czech Republic. Additional outputs are precipitation forecast of NWP models and other meteorological information related to storms prediction from meteorological institutions as Czech Hydrometeorological Institute (CHMI) [3].

Calculation of 3-hour interval of the Algorithm of Storm Prediction is shown in the Fig. 1:

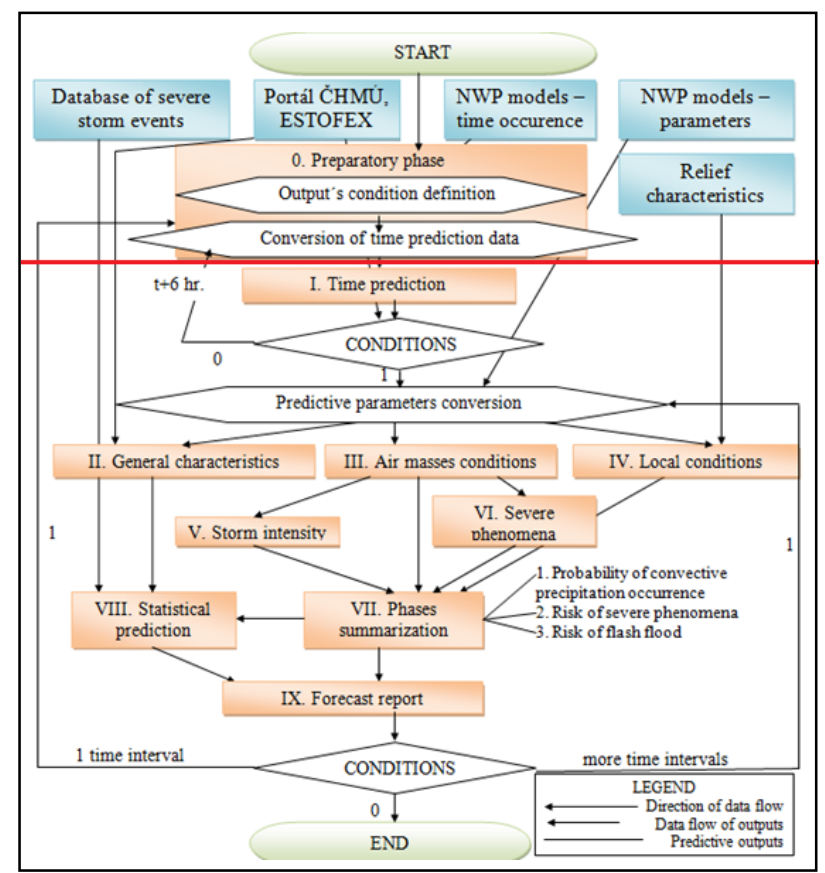

Fig. 1. Flowchart diagram of the Algorithm of Storm Prediction [3], [16], [17]

As can be seen in Fig. 1, the Algorithm of Storm Prediction is divided by red link in one third of this flowchart represented both algorithms. The Algorithm of transformation of output meteorological parameters (shown above red link) is described in more detail in this publication [18]. Second algorithm is subject to this article and is displayed below red link in the Fig. 1.

\subsection{Algorithm of transformation of output meteorological parameters}

The Algorithm of transformation of output meteorological parameters is partial application of the Algorithm of Storm Prediction. This algorithm is primarily determinate on processing the zero phase of the Algorithm of Storm Prediction for purpose transformation input meteorological parameters. These parameters are publicly available data of NWP models as raster images with most often used PNG and JPEG format. The main objective is calculation of coefficients, which may acquire values in interval of $0-3$. This algorithm is realized on the sequence of these steps:

- Online data processing from 17 servers of NWP models ALADIN, EURO4, GDPS, GFS, WRF ARW, WRF NMM a HIRLAM for the territory of Czech Republic.

- Creation unique graphic masks for processing data into database

- Dynamic data loading from NWP models and masks.

- Conceiving experimentally verified scale for transformation data.

- Output visualization of data transformation from NWP models to coefficients in interval of $0-3$.

Required data transformation is realized by sequences of these steps, whose outputs are processed in the Algorithm of transformation of output meteorological parameters [14], [18].

\subsection{Algorithm of conversion of meteorological model parameters}

This algorithm generates five predictive outputs in terms of the Algorithm of Storm Prediction:

- $\quad$ the Risk of flash flood (alg.),

- the Storm intensity (alg.),

- the Probability of precipitation occurrence and intensity(alg.),

- the Probability of precipitation occurrence (NWP models),

- $\quad$ the Risk of severe storm phenomena (alg.) [15].

Forecast outputs are computed as its probability values, which is converted on coefficient values with interval 0-3 according this formula:

$$
P_{h_{i}}=\frac{\sum_{j=1}^{k} v_{j} y_{i j}}{3 \sum n}
$$

where $y_{i j}$ are values of criteria matrix $Y$ and $v_{j}$ is weight of $j$-th criterion, which are the weights of predictive parameter coefficients. $\Sigma n$ represents the sum of predictive parameter of partial or main algorithm output [3], [16], [17]. 
The Risk of flash flood is the significant output of the Algorithm of Storm Prediction. This output is computed on the degree of soil saturation, the sum of potentially risky precipitation per 1 hour, the probability of convective precipitation occurrence, the storm intensity, the speed of the storm movement and summarization of severe storm phenomena. Coefficients values 2 and 3 represent important information about very high probability of flash floods for the given municipality with extended powers in terms of crisis management authorities. This information is used for purposes of early warning and possible realization of flood control measures.

The Storm intensity output is intended for forecast of the potential rainfall of convective storms and this is the part of calculation of the Risk of flash flood. The Storm intensity is computed on conditions of the daily/nightly instability of atmosphere, the complex support mechanisms of convection, the deep layer shear $0-6 \mathrm{~km}$ and the speed of storm movement. This output is also intended for comparison with output of the Service Integrated Warning System (SIWS) of CHMI.

The output of Probability of convective precipitation occurrence is basic outcome, which gives predictive information about distribution of convective precipitation. This output is calculated on other outputs as the Storm intensity and the Local conditions influencing the convection initiation in the ground layer of the atmosphere [3], [16], [17]. Classification of algorithm outputs is shown in Table 1 :

Table 1. Classification of evaluated algorithm outputs [16], [17]

\begin{tabular}{|c|c|c|c|}
\hline $\begin{array}{c}\text { Coeffici- } \\
\text { ents }\end{array}$ & $\begin{array}{c}\text { Rainfall } \\
\text { probability }\end{array}$ & $\begin{array}{c}\text { Storm intensity } \\
\mathbf{( m m} / \mathbf{h r} \text {.) }\end{array}$ & $\begin{array}{c}\text { Risk of } \\
\text { flash } \\
\text { flood }\end{array}$ \\
\hline 0 & $0-0,24$ & Weak $(0-29)$ & $\begin{array}{c}\text { Very } \\
\text { low }\end{array}$ \\
\hline 1 & $\begin{array}{c}0,25- \\
0,49\end{array}$ & $\begin{array}{c}\text { Strong (30- } \\
49)\end{array}$ & Low \\
\hline $\mathbf{2}$ & $0,50-$ & $\begin{array}{c}\text { Very strong } \\
(50-89)\end{array}$ & High \\
\hline $\mathbf{3}$ & 0,74 & $\begin{array}{c}\text { Extrem ely } \\
\text { strong (above } \\
90)\end{array}$ & $\begin{array}{c}\text { Very } \\
\text { high }\end{array}$ \\
\hline
\end{tabular}

\subsection{Verification of predictive outputs}

Verified predictive outputs are calculated on criterion Accuracy according this formula:

$$
A=\frac{a+d}{a+b+c+d} \times 100(\%),
$$

"where $a$ is the number of cases where the phenomenon was predicted and actually occurred; $b$ is the number of cases where the phenomenon was not predicted and actually occurred; $c$ is the number of cases where the phenomenon was predicted and did not actually occur, and $d$ is the number of instances when the phenomenon was not predicted and did not actually occur" [16], [17].

\subsection{Visualization of predictive outputs}

These predictive outputs are visualised into maps and tabular format, which are displayed on the main panel of application:

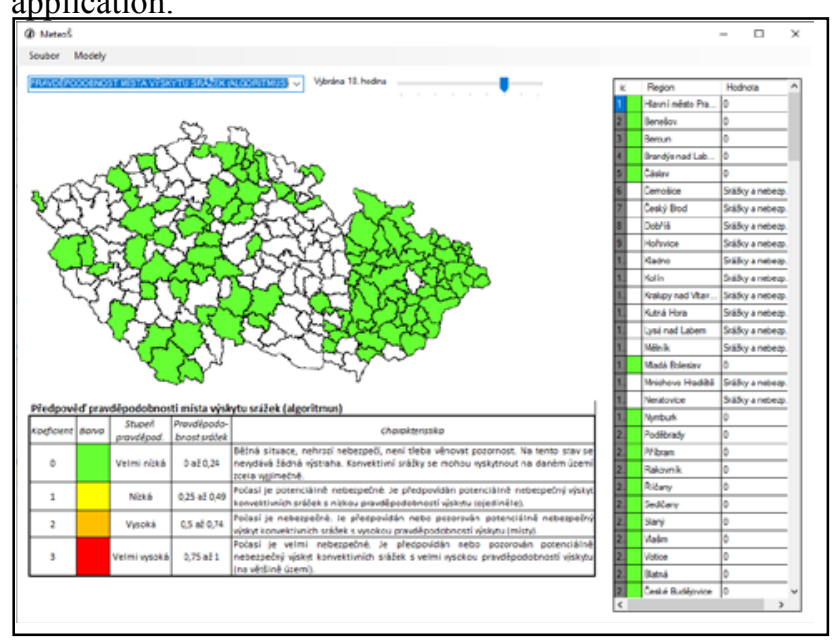

Fig. 2. The main panel of the Algorithm of conversion of meteorological model parameters [15]

Fig. 2 illustrates the main panel of the Algorithm of conversion of meteorological model parameters. This panel is divided into a control menu (a choice of eight prediction outputs and a prediction advance time after three hours), a map output (centre of the panel), a legend with the meanings of the coefficient values (below the map) and the coefficient values (right).

\section{Results}

This chapter is focused on results of predictive output verification as the Probability of convective precipitation occurrence, the Risk of flash floods and the Storm intensity, which are compared with outputs of NWP models and predictive warning information form SIWS of the CHMI. This verification is concentrated on the comparison of the success rate of predictive outputs computed manually in the MS Excel and software recalculated outputs of the Algorithm of Storm Prediction. The verification was created for 63 storm events of year 2015, 2016 and 2017.

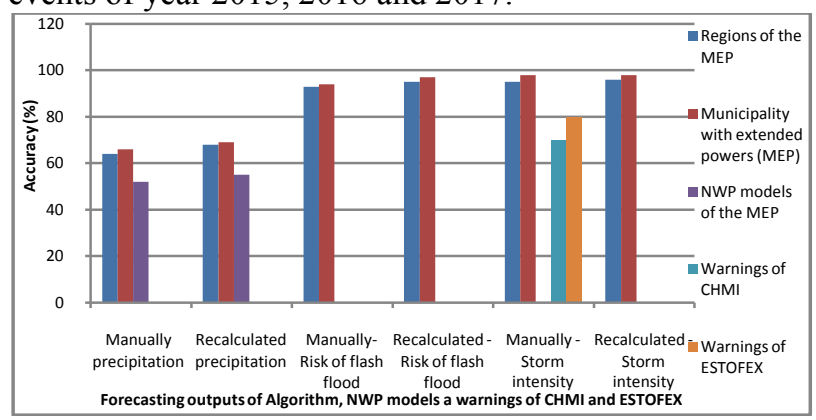


Fig. 3. The accuracy of predictive outputs of the Algorithm of Storm Prediction, NWP models and warning information of CHMI and ESTOFEX of year 2015

As can be seen in Fig. 3, the highest difference of predictions success rate was reached at the probability of convective precipitation occurrence against other outputs. At the same time, the success rate of this output is always lower than the forecast of storm intensity and the risk of flash floods. The main reason for the lower success and higher differences between manual and recalculated forecasts is that the prediction of the probability of occurrence of precipitation is the output calculated as the very first output of NWP model data and local relief characteristics. And for this reason, this output is burdened with the highest error of all outputs. The forecast of storm intensity and the risk of flash floods combine multiple predictions and therefore has a lower degree of uncertainty.

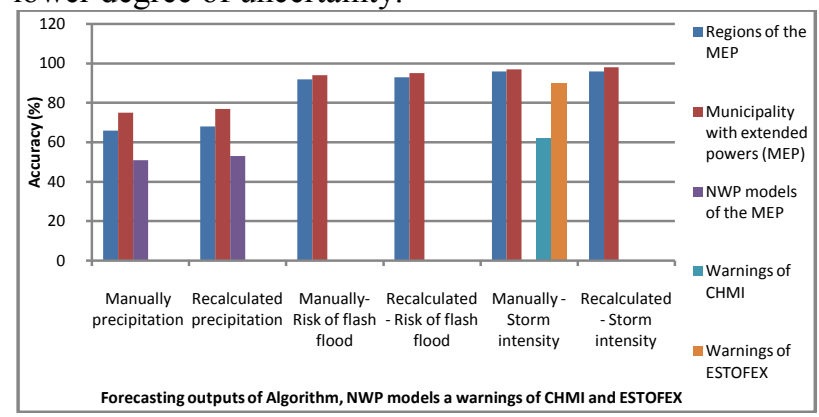

Fig. 4. The accuracy of predictive outputs of the Algorithm of Storm Prediction, NWP models and warning information of CHMI of year 2016

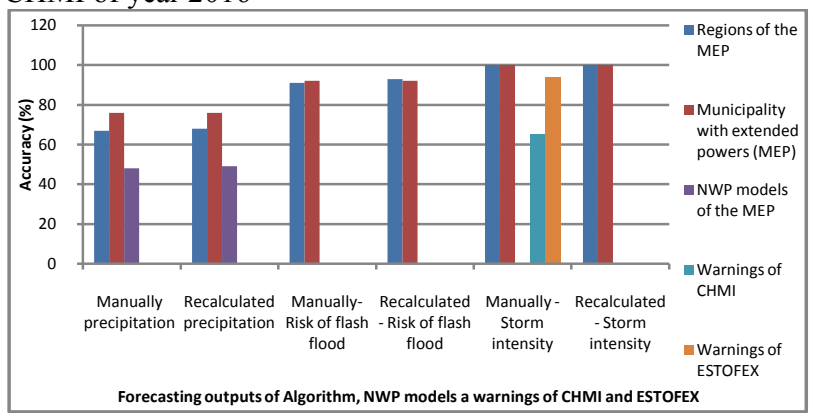

Fig. 5. The accuracy of predictive outputs of Algorithm of Storm Prediction, NWP models and warning information of CHMI of year 2017

Fig. 4 and 5 documents that the success rate of all forecasting tools is very similar, and most of the outputs have reached a growing trend compared to 2015. The difference between manual and recalculated outputs is lower than in Chart 1 due to more accurate calculation methods and more calculated situations than in 2015. The success of predictive outputs confirmed the appropriately chosen prediction parameters and methods used to calculate them.

\section{Conclusions}

The objective of this article was to provide information about support application the Algorithm of conversion of meteorological model parameters. This application is a part of new forecast tool - the Algorithm of Storm Prediction. This article was also focused on the success rate evaluation of the manually and computedprocessed three main predictive outputs which was verified on 63 storm events in years of 2015-2017.

Verified predictive algorithm outputs were the Probability of convective precipitation occurrence, Storm intensity and Risk of flash floods. The lowest success rate of forecasts and the same time the highest difference between manually and recalculated prediction was achieved for the Probability of convective precipitation occurrence approximately $4 \%$ in 2015 . On the other hand, the success rate of this output had the growing trend (up to $10 \%$ ) in 2016-2017 due to sufficient used amount forecast parameters, appropriately selected forecasting methods and increase the amount assessed storm situations. The success rate of the Storm intensity forecast and the Risk of flash floods were more than $20 \%$ higher than the Probability of convective precipitation occurrence just because of a combination of more calculated parameters and partial predictions. Simultaneously, the success rate of the Risk of flash floods and especially the Storm intensity was higher by $20-30 \%$ than predictive warning information of the SIWS CHMI. Higher success rate of these predictions is a beneficial assumption for the future implementation of the Algorithm of Storm Prediction in to the SIWS CHMI intended for early warning against torrential rainfall and flash floods.

The limitation of this study is the insufficient amount of the verified storm events. Future research will be focused on the testing and the verification of the tens to hundreds storm situations for purpose the configuration and the gradual increasing success rate of outputs of the Algorithm of Storm Prediction.

This work was supported by the project No. CEBIA-Tech LO1303, A2.4 - ICT for support of crisis management, Department of Security Engineering and the project No. VI20192022134 - A system of refined convective predictions precipitation for the regional territorial unit.

\section{References}

1. P. Kalmus, B. H. Kahn, S. W. Freeman, S. C. Van Den Heever, Monthly Weather Review, 147, 20 (2019)

2. R. A Houze, J. Wang, J. Fan, S. Brodzik, Z. Feng, Geophysical Research Letters. 46, 16 (2019)

3. D. Šaur, Information support for crisis management of the region in terms of assessment of flood events, 172 (2017)

4. D. Nerini, L. Foresti, D. Leuenberger, S. Robert, U. Germann, Monthly Weather Review, 147, 20 (2019)

5. J. Mejsnar, Z. Sokol, J. Minarova, Atmospheric Research, 213, 14 (2018) 
6. P. M. James, B. K. Reichert, D. Heizenreder, Weather and Forecasting, 33, 20 (2018)

7. V. Bliznak, M. Kaspar, M. Müller, P. Zacharov, Atmospheric Research, 224, 15 (2019)

8. J. Tian, J. Liu, D. Yan, L. Ding, Ch. Li, Atmospheric Research, 224, 10 (2019)

9. F. Gofa, D. Boucouvala, P. Louka, H.A. Flocas, Atmospheric Research, 208, 9 (2018)

10. G. R Herman, R. S. Schumacher, Journal of Hydrometeorology, 19, 13 (2018)

11. Ch. Liu, L. Guo, L. Ye, S. Zhang, Y. Zhao, T. Song, Natural Hazards, 92, 15 (2018)

12. R. Šercl, Proceedings of the Czech Hydrometeorological Institute, 60, 18 (2015)

13. D. Šaur, Algorithm of Storm Prediction: Technical specification (2018)

14. D. Šaur, R. Žák, J. Švejda, Algorithm of Transformation of Output Meteorological Parametres, 2018

15. D. Šaur, R. Žák, J. Švejda, Algorithm of Conversion of Meteorological Model Parametres, 2018,

16. D. Šaur, K. Víchová, MATEC Web of Conferences (EDP Sciences, Les Ulis, 2018)

17. D. Šaur, WSEAS Transactions on Environment and Development, 14, (2018)

18. D. Šaur, $8^{\text {th }}$ Computer Science On-line Conference 2019 (CSOC 2019), 12 (2019).

19. Czech Hydrometeorological Institute, Available at: http://portal.chmi.cz/files/portal/docs/meteo/om/siv s/bourky.html (1997 - 2018) 